\title{
APRENDENDO SOBRE O PASSADO POR MEIO DAS BIOGRAFIAS: ENTRA A PEDAGOGIA E A PRAGMÁTICA DA HISTÓRIA
}

Learning about the past by biography: enter the pedagogy and the pragmatics of history

Rafael Terra DALL' AGNOL *

Resumo: Este trabalho tem como objetivo analisar, a partir da obra do historiador João Manuel Pereira da Silva, a relação entre história e biografia no Brasil oitocentista. Juntamente a esse intuito, na segunda parte do artigo, busco avaliar como que, a partir de seus escritos literários, observam-se, em Pereira da Silva, os mesmos objetivos presentes no seu trabalho sobre as biografias. Com isso, busco compreender de que forma as biografias podem auxiliar na busca de esclarecimento sobre o passado, servindo como chave de acesso às experiências pretéritas. Junto a esse movimento, o artigo se propõe a demonstrar as especificidades encontradas nos trabalhos do autor de Plutarco Brasileiro.

Palavras-chave: História da historiografia, Historiografia brasileira, Século XIX.

Abstract: This work aims to analyze, based on the work of historian João Manuel Pereira da Silva, the relationship between history and biography in nineteenth century Brazil. Together with this intention, in the second part of the article, I try to evaluate how, from his literary writings, the same goals present in his work on biographies are observed in Pereira da Silva. It seeks to understand how biographies can help in the search for clarification about the past, serving as a key to access past experiences. Along with this movement, the article proposes to demonstrate the specificities found in the works of the author of Plutarco Brasileiro.

Keywords: History of historiography, Brazilian historiography, XIX century.

\section{PARTE I}

\section{O IHGB E A PRODUÇÃO DE BIOGRAFIAS}

Dentro do contexto do Brasil oitocentista, ao lado da história, à biografia também cabia a tarefa de escrever a história da nação. Já no discurso de inauguração do Instituto Histórico e Geográfico Brasileiro ${ }^{1}$, um lócus privilegiado para a construção do projeto nacional durante o Império e, de acordo com José Honório Rodrigues ${ }^{2}$, o marco inicial da historiografia disciplinada do país, há a preocupação com a produção sistemática de biografias.

\footnotetext{
*Doutorando em História - Programa de Pós-graduação em História - UFRGS - Universidade Federal do Rio Grande do Sul - Porto Alegre, RS - Brasil. Este artigo é uma adaptação de parte dos resultados de pesquisa da minha dissertação de Mestrado. E-mail: rhcprafael@ hotmail.com.

${ }^{1}$ Sobre o IHGB, ver: GUIMARÃES, Manoel Luiz Salgado. Historiografia e nação no Brasil: 1838-1857. Rio de Janeiro: EdUERJ, 2011.

${ }^{2}$ RODRIGUES, José Honório. “O Instituto Histórico e Geográfico Brasileiro”. In: RODRIGUES, José Honório. A pesquisa histórica no Brasil. São Paulo: Companhia Editora Nacional/MEC, 1978, pp. 37-40.
} 
De fato, no conhecido discurso de inauguração do IHGB, Januário da Cunha Barbosa, secretário perpétuo do Instituto, nas mais de nove páginas publicadas pela Revista, em 1839, destina um espaço considerável à reflexão sobre a importância das biografias. A epígrafe do texto pertencente ao historiador Alexandre de Gusmão remete à necessidade de trazer à luz os fatos notáveis da pátria. A referência mais adiante a Cícero também serve como elemento de autoridade para justificar a importância não somente da fundação do IHGB, mas também um estímulo aos seus membros para tão "audaciosa tarefa":

- Começamos hoje hum trabalho que, sem dúvida, remediará de alguma sorte os nossos descuidos, reparando os erros e enchendo as lacunas, que se encontrão na nossa historia. Nós vamos salvar da indigna obscuridade, em que jazião até hoje, muitas memorias da patria, e os nomes de seus melhores filhos; nós vamos assignalar, com a possível exactidão, o assento de suas cidades e villas mais notaveis, a corrente de seus caudalosos rios, a área de seus campos, a direcção de suas serras, e a capacidade de seus innumeraveis portos. ${ }^{3}$

Se para o cônego Barbosa, as melhores lições que se pode receber são dadas pela história, qual seria a melhor forma de aprendê-las? Na vida dos grandes homens, já que ali "aprende-se a conhecer as applicações da honra, a apreciar a gloria e a affrontar os perigos, que muitas vezes são causas de maior glória". ${ }^{4} \mathrm{O}$ exemplo não poderia ser outro do que o livro de Plutarco:

O livro de Plutarco (diz o barão de Morogues) he huma excellente escola do homem, porque offerece em todos os generos os mais nobres exemplos de magnanimidade; ahi se encontra descoberta toda a antiguidade; cada homem celebre ahi apparece com seu genio, com seus talentos, com suas virtudes e com a influencia que exêrcera sobre seu seculo [...]; ahi vidas brilhantes e mortes illustres ensinão a amar a gloria, a apreciar suas causas, a prever os seus resultados, e a acautelarmo-nos daquelles perigos que a seguem como sombras, porque (diz M. Thomaz) os homens que pesão sobre o universo tambem lutão com o seu proprio peso; logo apoz a gloria achão-se frequentemente occultos o desterro, o ferro e o veneno. ${ }^{5}$

A escolha do escritor de Queronéia como um bom exemplo a ser seguido permite constatar o aspecto mutável na relação entre biografia e história. Plutarco de Queronéia, em suas Vidas Paralelas, faz a distinção entre os dois gêneros: "Não escrevemos História, mas Vidas", está escrito no prefácio de Vida de Alexandre. Porém, dentro do regime de escrita da história no Brasil oitocentista, a biografia funcionava como importante modo de elaboração de experiências do passado. Compartilhando objetivos comuns, ambos os gêneros, não podem ser considerados como puros ou inalteráveis. Como ressalta o historiador Temístocles Cezar, a biografia dos grandes homens como portadora de exempla é um projeto de ordem

\footnotetext{
${ }^{3}$ BARBOSA, Januário da Cunha. "Discurso". Revista do Instituto Histórico e Geográfico Brasileiro, Rio de Janeiro, 1839, p. 13. Mantive a grafia original dos textos de época.

${ }^{4}$ Idem, p. 14.

${ }^{5}$ Ibidem.
} 
historiográfica. Ou seja, "não se trata de uma posição irrefletida, mas de um sinônimo aproximado do movimento da história. O mundo se transforma graça aos grandes homens". 6 Conclui-se com isso que o projeto biográfico proposto por Barbosa possuía uma verdadeira pertinência histórica.

Ora, a questão central entre a escrita biográfica e a histórica reside na importância atribuída à dimensão individual. Ou seja, em uma pergunta, a vida de um indivíduo pode esclarecer o passado? Em 1863, o historiador Johnn Gustav Droysen escreve que, se chamamos $A$ o gênio individual, ou seja, tudo o que um homem é, possui e faz, então este $A$ é formado por $a+x$, em que $a$ possui tudo aquilo que advém das circunstâncias externas, de seu país, de seu povo, de sua época, etc., e o $x$ representa a sua contribuição pessoal, a obra de sua livre vontade. ${ }^{7}$ O que interessa aqui é este $x$. Como pensá-lo em um momento no qual a biografia, ou melhor, as ações, as características, os acontecimentos individuais, cedem espaço para modelos históricos explicativos que privilegiavam uma visão totalizante e processual da história? Paradoxalmente, o século XIX propiciou um enorme campo de pensamento sobre o pequeno $x$, devido a autores que buscaram resguardar a dimensão individual da história, já que, segundo eles, a biografia possibilitaria também a compreensão do passado. Sabina Loriga, em Des possibilités d'une histoire biographique, reflete sobre essas questões. ${ }^{8}$ Para a autora, a história biográfica tem como um dos aspectos positivos compreender melhor a relação entre história e biografia. Ainda de acordo com Loriga, sobretudo no XIX, quando o pensamento histórico atinge seu apogeu, há dois momentos-chave que encorajaram uma separação entre biografia e história: o impacto da história filosófica e o divórcio entre a história social e a história política. ${ }^{9}$

\footnotetext{
${ }^{6}$ CEZAR, Temístocles. "Lições sobre a escrita da história: as primeiras escolhas do IHGB. A historiografia brasileira entre os antigos e os modernos". In: Estudos de historiografia brasileira. Rio de Janeiro: FGV, 2011, p. 108 .

${ }^{7}$ LORIGA, Sabina. O pequeno x: da biografia à história. Belo Horizonte: Autêntica Editora, 2011, p. 14.

${ }^{8}$ LORIGA, Sabina. "Des possibilités d'une histoire biographique”. Comunicação apresentada na conferência proferida em 25 de setembro de 2006 no IFCH/UFRGS. Texto cedido pela autora. Agradeço ao professor Evandro dos Santos a disponibilidade do texto. As traduções feitas são de minha inteira responsabilidade.

9 “A fronteira que separa a história da biografia foi sempre bastante contrastada, e nós podemos encontrar, em todas as épocas, historiadores que esperaram uma separação definitiva entre elas. Mas, na realidade, o fosso entre os dois gêneros se aprofundou, sobretudo, ao longo do século XIX, quando o pensamento histórico atinge seu apogeu. Eu gostaria de sublinhar dois momentos-chave que encorajaram uma separação definitiva. O primeiro remonta ao fim do século XVIII e ao início do século XIX e está ligado, sobretudo, ao sucesso e ao impacto da história filosófica, enquanto que o segundo momento, que foi desencadeado nas últimas décadas do século XIX pelos historiadores, atinge o seio da história e coincide com o divórcio entre a história social e a história política. [...] Houve, então, uma dupla despersonalização: a do passado e a do historiador, que pode falar como especialista, como perito, nunca como autor. Felizmente, também houve várias resistências a esse processo de despersonalização". Ibidem.
} 
Contudo, a perda de espaço da biografia também se deve, se tomarmos as considerações de Reinhart Koselleck ${ }^{10}$, à mudança no conceito de história. No caso brasileiro, a historiadora Maria da Glória de Oliveira, ao estudar a biografia como problema historiográfico, parte do estudo da dissolução do topos da historia magistra vitae e sua relação com a produção de biografias escritas pelos letrados do Instituto Histórico e Geográfico Brasileiro. ${ }^{11}$ Em síntese, a autora se questiona sobre que estatuto "as vidas de indivíduos ilustres" teriam para o trabalho do historiador em um momento no qual a história como disciplina buscaria mais a compreensão e explicação dos processos históricos em detrimento do caráter individual acerca do passado. Ainda seguindo a argumentação da historiadora, no esforço coletivo que deveria resultar na elaboração da história nacional, os trabalhos biográficos desempenhariam importante papel, mas relacionado a uma função moralizante e pedagógica da história. Esses aspectos demonstram ser a biografia um gênero em construção no contexto brasileiro do século XIX. Será dentro desse contexto de dúvidas, hesitações e reflexões sobre a utilização das biografias no trabalho do historiador que surge a obra Plutarco Brasileiro, de Pereira da Silva. ${ }^{12}$

\section{O INDIVÍDUO E A ORDEM DO TEMPO: CONTRA A FRAGMENTAÇÃO DO DISCURSO}

"Era Thomaz Antonio Gonzaga de estatura pequena, cheio de corpo: tinha physionomia clara e espirituosa, animada por dous olhos azues, vivos, e penetrantes [...]". ${ }^{13}$ É dessa forma que Pereira da Silva inicia a descrição do poeta mineiro conhecido pelo nome arcádico Dirceu. Posteriormente, ele acrescenta: “encantava com sua conversação alegre, jovial, e engraçada; suas maneiras delicadas e polidas attrahiam-lhe todos os corações". ${ }^{14}$ A aproximação entre leitor e biografado, feita por Pereira da Silva por meio da palavra, é importante na busca da inteligibilidade do passado. Descrever aqui significa fazer ver, se possível, ou auxiliar na montagem de um quadro de época presente na imaginação de quem lê, mas orientado por quem escreve. Em um primeiro momento, visto de uma perspectiva individual - o poeta - para vinculá-lo a um determinado contexto histórico e social. Além desse aspecto, a forma como

\footnotetext{
${ }^{10}$ KOSELECK, Reinhart. "História magistra vitae. Sobre a dissolução do topos na história moderna em movimento. In: KOSELLECK, Reinhart. Futuro passado: contribuição à semântica dos tempos históricos. Rio de Janeiro: Contraponto, 2006, pp. 41-60.

${ }^{11}$ OLIVEIRA, Maria da Gloria de. Escrever vidas, narrar a história: a biografia como problema historiográfico no Brasil oitocentista. Rio de Janeiro: Editora FGV, 2011.

12 Obra escrita em 1847 por Pereira da Silva. Nela estão reunidas vinte biografias sobre importantes personalidades do Brasil colonial. SILVA, João Manuel Pereira da. Plutarco Brasileiro. Rio de Janeiro: Em Casa dos Editores Eduardo e Henrique Laemmert, 1847. 2 v.

${ }^{13}$ SILVA, João Manuel Pereira da. Plutarco Brasileiro. op. cit., p. 175 (1V).

${ }^{14}$ Ibidem.
} 
Pereira da Silva retrata o biografado estimula a construção de uma empatia entre o leitor e o poeta, algo que será necessário haja vista os acontecimentos em que Gonzaga estará envolvido.

O que chama a atenção, no entanto, é o lugar destinado à descrição do autor de Cartas Chilenas $^{15}$ - entre o meio e o fim da obra. Normalmente, Pereira da Silva seguia uma sequência em que as primeiras páginas eram destinadas à apresentação do biografado, de forma quase sempre cronológica, para, depois de feita a biografia da personalidade escolhida, partir para a análise de seu trabalho enquanto homem de letras. Em relação a Tomás Antônio Gonzaga, ele inicia de forma diferente dos outros relatos. Ele começa pelo acontecimento mais trágico da vida do poeta: o seu envolvimento no que viria a ser conhecido como Inconfidência Mineira. Entre a chegada e a ida de uma fragata portuguesa, muitas coisas acabam sucedendo-se:

Em 9 de Julho de 1790 recebeu o Conde de Rezende, das mãos de Luiz de Vasconcellos e Souza, o governo do Estado do Brazil: um anno não tinha ainda decorrido, quando uma bella fragata portugueza, de nome GoIphinho, entrou no porto do Rio de Janeiro, trazendo a seu bordo os desembargadores Antônio Gomes Ribeiro, e Antônio Diniz da Cruz e Silva, nomeados pela Rainha D. Maria I, para que, unidos com o chanceller da Relação, Sebastião Xavier de Vasconcellos Coutinho, e outros magistrados da escolha do ViceRey, julgassem, em alçada extraordinária , e summarissimamente, os indiciados no crime de rebellião, que se tentara na capitania de Minas Geraes, segundo que haviam communicado a S. M. o Vice-Rey Luiz de Vasconcellos, e o governador e capitão general de Minas, Visconde de Barbacena. ${ }^{16}$

Algumas páginas adiante:

Mezes depois a mesma bella fragata, que de Lisboa trouxera os dous magistrados, que tinham julgado o processo, regressou á Lisboa levando os condemnados sacerdotes, e mais o doutor Domingos Vidal Barboza, José de Rezende Costa, pai, e filho, e outros degradados, que de lá seguiram para seus destinos de Sanctiago, e Cabo Verde. ${ }^{17}$

O que Pereira da Silva narra entre uma citação e outra são os acontecimentos referentes à Inconfidência Mineira, conforme já dito - desde a viagem feita por Tiradentes para a Europa e os E.U.A, passando pela montagem do plano da revolta e terminando nas condenações, degredos e morte dos envolvidos. Por ter muito o que relatar, afinal o movimento de 1789 foi - e continua sendo - de considerável importância na história do país devido às suas mais diversas ressignificações, Pereira da Silva pode correr o risco de perder-se na sua narração em meio ao excesso de informações disponíveis que se sucedem em meio à descrição dos acontecimentos. Ora, como forma de construir um retrato de época em que a figura do biografado é inserida torna-se importante a busca de um elemento capaz de manter certa

\footnotetext{
${ }^{15}$ Gonzaga, Tomás Antonio. Cartas chilenas. São Paulo: Companhia de Bolso, 2006.

${ }^{16}$ Idem, p. 167.

${ }^{17}$ Ibidem.
} 
unidade e coerência à obra. Como encontrar essa ordem? A partir dos percursos individuais. Isto é, são os personagens que organizam a narrativa seja no tempo, seja no espaço. ${ }^{18}$ Vejamos um exemplo.

Quando Pereira da Silva relata os planos dos participantes do movimento de criar na capitânia uma república, universidades de estudos, manufaturas etc., a tentativa de ter o apoio do povo, utilizando como pretexto as notícias espalhadas de que se limitaria o número de escravos a que cada proprietário tinha direito e a cobrança da derrama, logo após surge a figura de Tomas Antonio Gonzaga buscando ordenar esse conjunto de acontecimentos:

Thomaz Antônio Gonzaga recebeu n'este entretanto carta de nomeiação de desembargador para a Relação da cidade da Bahia, e ordem de partir: apressou-se á aconselhar ao intendente, e á junta da fazenda, que exigissem o pagamento dos atrazados conjunctamente com a importância da derrama do anno, de combinação, como é de suppôr, com os revolucionários, a fim de augmentar a odiosidade publica contra o governo, e de validar a noticia espalhada adrede pelos conjurados: verdade é que elle no seu interrogatório negou sempre cumplicidade no crime, e protestou por sua innocencia; assegurando que dera este conselho para o fim de perfeitamente conhecer o governo que era tal cobrança impossível, e por este conhecimento deliberarse a Rainha á perdoar aos devedores. ${ }^{19}$

Mais do que somente inserir o poeta nos desdobramentos do movimento, algo por si só evidente haja vista a importante participação que Gonzaga teve, parece que os acontecimentos se sucedem, ou em melhores termos, encontram inteligibilidade e sentido por meio do biografado. A história acontece mediante o autor de Marília de Dirceu ${ }^{20}$, que, inexoravelmente, não tem controle sobre suas consequências. Com isso, a pergunta referente à fórmula proposta por Droysen aqui é atualizada ao pensarmos no papel do pequeno " $x$ ". ${ }^{21}$ Qual é o seu papel dentro de Plutarco Brasileiro?

Primeiramente, é necessário acentuar um aspecto importante. Não se trata de qualquer pessoa. Como já notado na análise de trechos do discurso de inauguração do IHGB, feita algumas páginas acima, o projeto biográfico proposto pelo cônego Barbosa tinha verdadeira pertinência histórica, no sentido de que a história ocorria graças à ação do indivíduo, no caso em questão, do chamado "grande homem”. Como argumenta a historiadora Maria da Glória de Oliveira, "as reflexões filosóficas do final do século XVIII, na mesma medida em que contribuem para a constituição da concepção de história como agente e sujeito de si mesma,

\footnotetext{
${ }^{18}$ O historiador Evandro dos Santos, em sua dissertação de mestrado, também chama a atenção para esse aspecto ao referir-se a Varnhagen. SANTOS, Evandro dos. Tempos da pesquisa, tempos da escrita: a biografia em Francisco Adolfo de Varnhagen (1840-1873). UFRGS, 2009, p. 105. Dissertação de mestrado.

${ }^{19}$ SILVA, João Manuel Pereira da. Plutarco Brasileiro. op. cit., p. 170 (1V).

${ }^{20}$ GONZAGA, Tomás Antonio. Marília de Dirceu. Porto Alegre: Leitura XXI, 2004.

${ }^{21}$ LORIGA, Sabina. O pequeno x: da biografia à história... op. cit., p. 14.
} 
também colocam em xeque a categoria antiga de herói ou de varão plutarquiano, em nome de um novo personagem: o grande homem". ${ }^{22}$ Quais seriam, portanto, as características desse ser “excepcional"? Vinculada à cultura das Luzes, essa noção representa o surgimento de uma nova exemplaridade e pedagogia heroicas. Será mediante as ações do grande homem que se tornará possível compreender o espírito de uma época. No Brasil oitocentista, embora se encontrem menções ao modelo de exemplaridade plutarquiano, cujo exemplo a que se pode referir é o próprio título da obra de Pereira da Silva, a ênfase na noção do grande homem e tudo o que ela representa estará presente:

À luz dos princípios enunciados pelo cônego Cunha Barbosa, o projeto de escrita da história nacional desdobrava-se em múltiplas vias de realização, entre as quais estava a constituição de uma galeria de nomes dignos, a serem memorizados por seus grandes feitos em prol da nação. Não obstante a evocação recorrente ao modelo de exemplaridade plutarquiano, a noção-chave implícita na formação do panteão brasileiro será a do grande homem das Luzes, louvado por personificar a excelência do homem letrado, benfeitor da humanidade e sobretudo dotado de virtudes exemplares como servidor do Estado. A publicação regular e em série das biografias desses personagens sugere, portanto, que eles encarnam valores coletivos celebrados pela sociedade do Segundo Reinado. ${ }^{23}$

O espaço destinado à dimensão individual dentro de Plutarco Brasileiro com isso extrapola a mera escolha de um formato que o autor decidiu dar a sua obra para agradar aos seus leitores. Tomas Antonio Gonzaga aparece como elemento aglutinador que mantém coesão à narrativa. Junto a isso é possível também aprender sobre o passado, ou seja, a biografia ensina. Em outros termos, biografia e história então se encontram. Longe de ser um caso reservado ao poeta mineiro, quando o historiador escreve sobre José Bonifácio é possível encontrar os mesmos aspectos observados acima.

Nascido em 13 de junho de 1765, Bonifácio teve muitas funções e interesses de estudo. Foi estadista, naturalista e poeta, além de ter tido papel decisivo para a efetivação da Independência do Brasil. Pela sua importância para a história do país, ele ocupa lugar considerável na obra de Pereira da Silva. As mais de quarenta páginas destinadas à sua biografia abrangem resumidamente a vida do patriarca e seu trabalho enquanto um homem de letras. A relação presente entre o particular e o geral, assim como em Tomas Antonio Gonzaga, é representativa da tentativa de Pereira da Silva de não menosprezar, e tampouco sobrevalorizar, um ou outro, mesmo quando ocorre um descompasso entre ambos, conforme se pode ler abaixo:

Emquanto a Europa estremecia sob o peso dos acontecimentos políticos, que tão cruelmente magoaram os últimos annos do século XVIII; emquanto o

\footnotetext{
${ }^{22}$ OLIVEIRA, Maria da Gloria de. Escrever vidas... op. cit., p. 17.

${ }^{23}$ Idem, pp. 20-21.
} 
mundo como que tomava nova face, já movido pelo estrepito horroroso da revolução franceza - e já espantado com os espectaculos novos e variados, por que passava; - emquanto por toda a parte se não tratava senão de guerra, - José Bonifácio de Andrada e Silva tinha unicamente olhos e pensamento para o estudo das sciencias; - para elle, e-só para elle applicava seus cuidados, e sua ambição! ${ }^{24}$

E logo adiante:

Dez annos durou a peregrinação scientifica de José Bonifácio de Andrada e Silva! E - dez annos dos tempos críticos da Europa! — Dez annos, em que todas as nações se levantavam para luctar; - em que desde o Newa até o Guadalquibir,- desde o Dee até o golpho de Tarento - tudo eram levas de soldados - retinir de armas, - fogo de combates —, e ribombo de

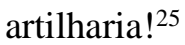

No que condiz a sua ação política ela é vista com algumas ressalvas por Pereira da Silva. Após o fim da sua sossegada vida como naturalista, o patriarca da independência é inserido no conjunto de acontecimentos que o historiador descreve que culminaram na ruptura política com Portugal:

Portugal havia aceitado o regimen constitucional, e nomeado côrtes para tratarem dos públicos negócios. EI Rey D. João VI se retirara para Lisboa, deixando no Rio de Janeiro seu filho primogênito o príncipe D. Pedro, na qualidade de regente do Brazil. As côrtes portuguezas, no intuito de subordinar mais fortemente o Brazil a Portugal, ordenaram por decretos de 29 de Setembro de 1821, que ficassem extinctos os tribunaes da chancellaria e do thesouro, a junta do commercio, e varias repartições centraes que EIRey D. João VI estabelecera no Brazil, quando o elevara em 1815 á calhegoria de Reyno; e por outro decreto de egual dacta que o príncipe D. Pedro regressasse a Portugal. ${ }^{26}$

Diante desse período conturbado, a figura de José Bonifácio será importante, de acordo com o autor, devido a sua liderança e capacidade de articulação.

Foi geral o descontentamento dos Brazileiros, e unisono seu grito de guerra. José Bonifácio de Andrada e Silva se collocou á frente do movimento. Bateulhe de rijo o patriótico coração. Desamparou casa e família. A junta provincial se reunio em S. Paulo em 24 de Dezembro de 1821. Foi José Bonifácio de Andrada e Silva o vice-presidente. A' sua voz adheriram todos. Uma representação redigio em nome da junta, dirigida ao príncipe regente, na qual se lhe implorava a graça de suspender sua viagem para a Europa, e de se conservar no Brazil. José Bonifácio de Andrada e Silva veio em pessoa ao Rio de Janeiro trazer ao príncipe regente esta representação. Este primeiro passo encontrou apoio no povo do Rio de Janeiro, e no de Minas Geraes. O príncipe regente acquiesceu aos desejos dos Brazileiros, unio sua causa á causa d'lles, sua gloria á gloria d'elles, e sua historia á historia do Brazil. ${ }^{27}$

Ao longo da biografia, o autor busca vincular à Bonifácio um sentimento patriótico capaz de fundar uma nova nação. Eram momentos decisivos para o destino que se queria para

\footnotetext{
${ }^{24}$ SILVA, João Manuel Pereira da. Plutarco Brasileiro. op. cit., p. 115 (2V).

${ }^{25}$ Idem, p. $116(2 \mathrm{~V})$.

${ }^{26}$ Idem, pp. 124-125 (2V).

${ }^{27}$ Ibidem.
} 
o país. Aos olhos de quem lê a obra, por outro lado, se não havia mais a necessidade de criar um novo país e com ele um sentimento de pertencimento que não existia, tinha-se como tarefa a manutenção da monarquia depois do período conturbado trazido pelas chamadas revoluções liberais da década de quarenta. O que esperaria o leitor da obra com a narração de todos esses fatos? Difícil saber exatamente. No entanto, a biografia, ainda vinculada a uma história que não recusa seu papel de magistra vitae, auxiliaria na demonstração de exemplos e atitudes a seguir e a evitar. Pois bem, se o sentimento patriótico demonstrado por José Bonifácio devia ser relembrado e elogiado, seus erros políticos representam um exemplo oposto.

Proclamada a Independência, os primeiros problemas surgem advindos das discussões em torno da nova Constituição. As divisões e os conflitos de opiniões dos diversos "partidos" existentes terminaram por desencadear uma atitude autoritária de D. Pedro I. Ele dissolverá à Assembleia Constituinte de 1823, levando à deportação de José Bonifácio. Como resultado, o reconhecimento de erros tanto do imperador quanto do patriarca:

Si José Bonifácio de Andrada e Silva commetteu graves erros-já quando ministro adoptando como seu um partido extremo, e extremo democrático, elle ministro de uma monarquia,- - já quando chefe de opposição, e fora do poder, combatendo o governo de modo a diluir-lhe os fundamentos e a tirarlhe a força moral de que todo o governo carece,- - e particularmente um governo que nascia de uma revolução, e que guarda portanto em seu seio vestígios de sua origem desorganisadora; - erros commetteu também D. Pedro I, empregando a arma da violência, que apenas presta força momentânea, e estraga a própria mão que d'ella se serve ${ }^{28}$

As biografias de Thomas Antonio Gonzaga e José Bonifácio de Andrade e Silva possibilitam vislumbrar algo presente em boa parte das trajetórias de vida inseridas na obra de 1847. A figura do biografado, sendo realçada e também, em alguns momentos, criticada, é vista como um elemento constituinte para manter certa unidade a narrativa, mediante a sucessão de descrições dos vários acontecimentos passados. Com isso, em Plutarco Brasileiro biografia e história partilham a mesma função, já descrita nesse trabalho, relacionada à questão nacional. A elas é conferido o papel de narrar a história da nação. Pode-se considerar ser isso uma tônica no período, desde o chamamento feito por Cunha Barbosa, passando pela seção destinada às biografias dentro do IHGB. O que é interessante de observar é que mesmo Pereira da Silva se inserindo nessa linha de autores responsáveis por escrever a história do país e estimular no leitor um apreço pela nação, ele o faz de maneira a suscitar algumas críticas após o lançamento do primeiro volume do livro. Outro aspecto, porém, aparece também na obra e diz respeito à

\footnotetext{
${ }^{28}$ Idem, p. 133.
} 
retórica da nacionalidade. O retorno à biografia de Gonzaga nos possibilita observar essa questão.

\section{A RETÓRICA DA NACIONALIDADE}

Conforme destaca Temístocles Cezar, a retórica da nacionalidade constituía um recurso, um discurso histórico destinado a persuadir os brasileiros de que eles compartilhavam de um passado em comum e, por consequência, também de um presente. ${ }^{29} \mathrm{Em}$ seu artigo A retórica da nacionalidade de Varnhagen e o mundo antigo: o caso da origem dos tupi, ele acrescenta que ao lado da história e da geografia, disciplinas que, no século XIX, passaram por alterações epistemológicas na tentativa de consolidar suas posições como ciência, juntamente com a literatura e, posteriormente, a etnografia "buscavam não apenas singularizar essa retórica da nacionalidade, ou seja, conter e resistir à dispersão do discurso, mas também procuravam constituir-se como campos de saber que explicassem a existência de uma nação ao longo de tempo formada por 'brasileiros", 30

Em Plutarco Brasileiro, no entanto, a retórica da nacionalidade encontra uma diferente modulação na biografia do poeta Thomas Antonio Gonzaga. Isto é, o debate principal não estava na tentativa de persuasão dos brasileiros para esse passado em comum, mas sim sobre a origem do biografado. Em Gonzaga isso aparece quando surgem dúvidas a respeito da sua origem. Com isso, a comprovação documental se faz pertinente, o que mostra que, mesmo se em uma primeira leitura do trabalho de Pereira da Silva identifica-se a predominância da historia magistra vitae, isso não exclui a necessidade de obediência a critérios que começavam a ser tornar importantes na escrita da história no século XIX. Pereira da Silva sabe da importância do poeta, pois tanto Portugal quanto Brasil pleiteavam para sua nação o nascimento dele. Cabe ao historiador, escrevendo biografias, resolver o impasse.

Um documento extrahido ultimamente do livro das matriculas da Universidade de Coimbra, de folhas 201, e do anno lectivo de 1763, attesta que Thomaz Antonio Gonzaga, matriculando-se no $1 .^{\circ}$ de Outubro, se declarára natural do Porto. ${ }^{31}$

O documento citado fora conseguido pelo Sr. Dr. José Maria do Amaral e encontravase no IHGB. A fim de comprovar a veracidade ou não da documentação, o autor relata que, por mais que o poeta tenha passado sua infância na Bahia, a declaração combina perfeitamente com o fato de seu pai ter sido transferido para a cidade do Porto. Coincidindo as datas, a veracidade

\footnotetext{
${ }^{29}$ Cf. CEZAR, Temístocles. L'écriture de l'histoire au Brésil au XIX siècle. Essai sur une rhetórique de la nationalité. Le cas Varnhagen. Tese de doutorado em história. Paris: EHESS, dois tomos, 2002.

${ }^{30}$ CEZAR, Temístocles. "A retórica da nacionalidade de Varnhagen e o mundo antigo: o caso da origem dos tupis". In: Estudos sobre a escrita da história. Rio de Janeiro: 7Letras, 2006. p. 29-41

${ }^{31}$ Idem, p. 176.
} 
do documento é atestada. Com isso, surge um aparente problema, pois como estimular a nacionalidade brasileira em gestação com um português nascido no Porto? Não há maiores complicações aqui. Há apenas fortuna: “Que importa pois que um acaso, e puro acaso, o fizesse nascer em Portugal? A sua gloria é gloria do Brazil, porque foi o Brazil terra de seu pai; porque no Brazil viveu Thomaz Antonio Gonzaga sua infância, e quasi toda a sua vida". E completa: "e porque pelo Brazil padeceu, e penou quando se ligou com outros Brazileiros anciosos de libertarem sua patria do jugo portuguez, e de a declararem independente". 32

$\mathrm{Na}$ verdade, como atesta Armelle Enders, a questão da origem daqueles a quem as biografias se destinavam tinha importância sim. Como exemplo, podem-se aludir às trocas de nomenclaturas feitas na sessão das biografias dentro da Revista do IHGB. Desde "Biografias de brasileiros distintos ou de indivíduos ilustres que serviram no Brasil" até "Biografias de brasileiros distintos ou de pessoas eminentes que serviram no Brasil ou ao Brasil”, os debates se condensavam na problemática de saber, afinal, quem era brasileiro e quem não o era. ${ }^{33}$ Além disso, no ano de 1854 coube a dom Romualdo Antônio de Seixas, então arcebispo da Bahia, a incumbência de provar, a contragosto, que o padre Antônio Viera nascera em Portugal. ${ }^{34}$

Após o fim do processo decorrente do movimento de 1789, não coube a morte ao poeta, mas sim o degredo:

E um brigue de guerra, pelo mesmo tempo, recebeu á seu bordo todos os mais condemnados, entre os quaes se contavam Thomaz Antônio Gonzaga, Ignacio José de Alvarenga Peixoto, Francisco de Paula Freire de Andrade, e José Alves Maciel, e os foi descarregando pelos presídios, a que eram reservados, como Ambaca, Benguela, Massangano, Cambambe, Pedras de Angoche, Moçambique, Macúa, rios de Senna, Inhambane,e Maximba.

Assim os homens mais reputados, e mais illustres d'aquella época, foram arrancados aos braços de suas famílias, lançados nas masmorras condemnados, e condemnados seus filhos innocentes - e além do oceano longe da pátria — aqui e ali dispersos — cada um isolado — ou tragaram sofírimentos atrozes até que lhes chegou o dia venturoso de regressarem ao Brazil, - fortuna que coube apenas a três ou quatro de tantos - ou n'esses pestilentos climas, no meio de insalubres águas, e de terras ressequidas - por entre os negros selvagens e bárbaros — viram acabar seus dias, sem que á hora derradeira da existência — uma voz amiga os consolasse á cabeceira. ${ }^{35}$

A comparação com o que acontecia na França possibilita ao leitor a ampliação do que acontecia no mundo:

Admirável contraste formam estas cousas do mundo! No mesmo anno de 1792, emquanto os republicanos de França julgavam, e condemnavam os

\footnotetext{
${ }^{32}$ Idem, p. 177.

${ }^{33}$ ENDERS, Armelle. Os vultos da nação: fábrica de heróis e formação dos brasileiros: Rio de Janeiro: Editora FGV, 2014, pp. 175-234.

${ }^{34}$ Oliveira oferece um mapeamento pormenorizado da discussão em torno da naturalidade do padre Antônio Vieira. Ver: OLIVEIRA, Maria da Gloria de. Escrever vidas... op. cit., pp. 101-104.

${ }^{35}$ SILVA, João Manuel Pereira da. Plutarco Brasileiro. op. cit., pp. 174-175 (1V)
} 
monarquistas, os monarquistas de Portugal julgavam também, e egualmente condemnavam os republicanos do Brazil; no mesmo anno de 1793, em que subia ao cadafalso o monarcha descendente do glorioso S. Luiz, egual sorte padecia o republicano Joaquim José da Silva Xavier. ${ }^{36}$

Thomas Antônio Gonzaga viveu quinze anos em Moçambique. O degredo tornou seu corpo débil, mas o pensamento ainda alimentava esperanças de salvação. Passando o tempo, contudo, o corpo recuperou suas forças, porém o espírito é que foi vítima de enfermidades: "Quando o corpo reganhou forças, o espirito desamparou-o: nem Marilia, nem o Brazil, nem a poesia lhe correram mais a lembrança [...]" ${ }^{37}$ Em 1808, é enterrado na Bahia. Com sua vida, o leitor pode espalhar-se naquele que lutou para ver seu país de adoção desvencilhar-se do jugo português - nas palavras de Pereira da Silva -, assim como pode aprender sobre os acontecimentos que se deram em Minas Gerais, durante o final do século XVIII. O final triste, talvez, sirva de alerta de que a luta pela formação da nação brasileira é mais importante, quem sabe, do que a própria dimensão individual daquele que dela participa.

\section{PARTE II}

\section{HISTÓRIA, BIOGRAFIA, LITERATURA}

Alguns anos antes da publicação do primeiro volume de Plutarco Brasileiro ter chegado ao conhecimento do público, outro trabalho de Pereira da Silva é divulgado e posto à venda. Trata-se de Parnaso Brasileiro ou Seleção de poesia dos melhores poetas brasileiros desde o descobrimento do Brasil precedida de uma introdução histórica e biográfica sobre a literatura brasileira $^{38}$. Essa obra, composta de dois volumes, o primeiro de 1843 e o segundo publicado cinco anos depois, é, como o próprio nome diz, uma coleção feita pelo autor reunindo um conjunto de poesias representativas de um período e de uma época. Havia, por outro lado, um objetivo semelhante à coleção proposta por Januário da Cunha Barbosa, editada entre 1829 e 1831. Ou seja, a coletânea deveria ser útil na medida em que estimulasse no leitor um gesto imitativo. Conforme as palavras do cônego Barbosa, "empreendi esta coleção das melhores poesias dos nossos poetas, com o fim de tornar ainda mais conhecido no mundo literário o gênio daqueles brasileiros", para que eles pudessem "servir de modelos, ou de estímulo à nossa briosa mocidade, que já começa a trilhar estrada das belas letras, quase que abandonada nos últimos vinte anos dos nossos acontecimentos políticos". ${ }^{39}$

\footnotetext{
36 Ibidem.

${ }^{37}$ Idem, p. 184 (1V).

${ }^{38}$ SILVA, João Manuel Pereira da. "Parnaso Brasileiro". In: ZILBERMANN, Regina; MOREIRA, M. Eunice. $O$ berço do cânone: textos fundadores da história da literatura brasileira. Porto Alegre: Mercado Aberto, 1998, pp. 143-181.

${ }^{39}$ BARBOSA, Januário da "Parnaso Brasileiro". In: ZILBERMANN, Regina; MOREIRA, M. Eunice. O berço do cânone: textos fundadores da história da literatura brasileira. Porto Alegre: Mercado Aberto, 1998, pp. 75-88.
} 
Apesar de algumas críticas ${ }^{40}$, a obra de Pereira da Silva inseria-se dentro da já citada retórica da nacionalidade. A ausência de critérios mais precisos para a escolha de seu panteão, embora o autor tenha se preocupado com a ordenação cronológica de sua coleção, poderia ser deixada em segundo plano. Existia uma necessidade mais pragmática presente em Parnaso Brasileiro. A literatura estava inserida dentro da história da nação. A busca de suas origens no passado corresponderia a um interesse vigente no presente. Quer dizer, mais que mera curiosidade, com o estudo da literatura podia-se demonstrar a existência de um passado ilustrado no país. E isso auxiliaria no aperfeiçoamento de sua escrita no presente. Não é outro o principal objetivo de Pereira da Silva, de acordo com suas palavras:

O Parnaso Brasileiro tende a grandes e nobres fins - reabilitar obras já esquecidas - lembrar nomes que ilustraram seu país - dar emulação aos poetas modernos, para realizarem seus voos majestosos, na certeza de que serão ouvidas suas vozes, e aplaudidos seus esforços - chamar enfim o gosto e a atenção dos brasileiros para a literatura de seu país. ${ }^{41}$

$\mathrm{Na}$ sua Introdução histórica e biográfica sobre a literatura brasileira, o historiador percorre os séculos XVI, XVII e XVIII. Sobre o primeiro, não havia espaço para a formação de uma literatura eminentemente nacional. O início da colonização, os conflitos entre portugueses e indígenas, a catequização dos índios, a defesa do território das ameaças das nações estrangeiras constituíam obstáculos para o seu surgimento. Tinha-se muito trabalho a fazer. Contudo, a poesia foi o primeiro ramo da literatura, cultivada pelos chamados povos do Brasil. Apenas alguns indivíduos isolados eram dignos de nota: “[...] durante o século XVI, apenas de algum brasileiro, de algum homem, que respirasse, nascendo, a atmosfera de amor e de delicias deste país novo e encantador, se contam versos e poesias, pela mor parte latinas, que constituem toda a literatura brasileira do século XVI". ${ }^{42}$ Esse seria justamente o problema da literatura dessa época. A mera imitação do que vinha de fora reduzia a capacidade imaginativa do poeta. Para Pereira da Silva, a inspiração deveria vir de dentro do país:

E em vez de desprenderem suas vozes livres como a aragem folgazona do vento, em vez de largarem os vôos a sua imaginação inspirada, como as cadeias ao prisioneiro, em vez de com o pensamento percorrerem esse mundo novo, todo de ilusões e grandezas, todo de imagens e fantasias, esse mundo, que o céu puro, como a pura Virgem, abria olhos do filho do país, os poetas de então como os dos séculos XVII e XVIII, eram meros copistas e imitadores

\footnotetext{
${ }^{40}$ Nas palavras do crítico Santiago Nunes Ribeiro, "[...] a obra de que tratamos tem o defeito de não satisfazer em tudo aos desejos dos curiosos. Estranha-se nela a falta de muitas composições tão primorosas como as escolhidas. [...] ela peca pelo defeito oposto àquele que se notou nos cadernos que com título idêntico publicara o Sr. Cônego Januário. Nestes figuram certos versos menos medíocres que não deviam entrar numa obra semelhante; naquela em vão se buscam certas peças de mérito subido, e que devem ter lugar numa seleção perfeita". RIBEIRO apud ZILBERMANN e MOREIRA. O berço do cânone: textos fundadores da história da literatura brasileira. Porto Alegre: Mercado Aberto, 1998, p 149.

${ }^{41}$ SILVA, João Manuel Pereira da. "Parnaso Brasileiro". op. cit., p. 179.

${ }^{42}$ Idem, p. 157.
} 
dos vates lusitanos, e celebravam antes os amores cavalheirescos dos galhardos portugueses, seus combates, e suas lidas de guerra, do que as belezas naturais do Brasil, com sua grandeza e majestade, com suas flechas e seus cocares. ${ }^{43}$

O século XVI, o da infância, apenas foi um prenúncio do que viria posteriormente. No período subsequente a literatura brasileira começaria a dar seus mais avançados passos. Embora a temática ainda fosse de inspiração predominantemente alheia à jovem colônia, de acordo com a citação acima, a "criança" estava pronta para desenvolver-se. Não obstante, o que chama atenção no decorrer do texto de Pereira da Silva é a constante menção à imaginação e sua relação seja com a natureza exuberante, seja com o poeta que nela se apoia. Vejamos um exemplo. Ao elogiar o que ocorreu no século XVII, o autor compara o Brasil com outros países para demonstrar a nossa qualidade literária. Em forma de pergunta, ele escreve: "Percorrei essas páginas dos estados americanos do Norte, segui essa longa enfiada de história das diversas nações, e achai-me uma, cujos filhos, logo ao princípio, provassem maior aptidão para tudo quanto existe de glorioso no domínio da imaginação?"44 Ainda sobre esse mesmo período, séc. XVII, na reflexão do autor sobre a poesia feita nessa época, a paisagem, e tudo o que ela contém, inspira o poeta e aquece sua imaginação:

A natureza faz poetas aos brasileiros, inspira-os no berço; as árvores, os pássaros, as cascatas, os rios, as montanhas; esse límpido céu, que, com o manto azul claro, os acoberta, essa atmosfera pura e doce, que lhes sorri desde a infância; esse oceano majestoso, que chora e brinca, geme e folgueia sobre suas arenosas praias, tudo lhes aquece a imaginação, lhes eleva o pensamento, lhes aviva o entusiasmo, e lhes abre as asas à inteligência, essa soberba filha do céu, que purifica e diviniza o homem. ${ }^{45}$

A falta de uma cor local que fosse eminentemente brasileira e representativa da nossa nacionalidade também afeta, em boa medida, a literatura do século XVIII. Faltava para nossos escritores, na visão do autor de Parnaso Brasileiro, a entrega livre à sua imaginação, pois isso somente poderia ser feito na medida em que a temática escolhida para a composição das obras fosse inspirada e surgisse de dentro do país. Para o autor, há um descompasso entre os letrados do período e as mudanças pelas quais o país estava passando, embora já existissem prenúncios de uma literatura nacional. Por um lado, questiona-se Pereira da Silva, "como não exprimiam eles [os poetas e escritores do século XVIII] essa idéia então em embrião, e que começava a compreender o povo do Brasil, como a de sua regeneração política, de sua futura nacionalidade?" Por outro, reconhece-se já nesse momento na literatura do período, “através de

\footnotetext{
${ }^{43}$ Ibidem. Grifo meu.

${ }^{44}$ Idem, p. 161. Grifo meu.

${ }^{45}$ Idem, p. 162. Grifo meu.
} 
seu prisma, a sua nacionalidade, a sua origem, nova e sagrada" ${ }^{46}$ Esses aspectos, não obstante, dificultam o livre imaginar dos escritores nascidos no Brasil, já que ela estava condicionada a fatos, acontecimentos, cores e belezas alheias:

\begin{abstract}
A literatura brasileira do século XVIII, seguindo as mesmas pisadas das literaturas dos diversos estados da Europa, máxime da portuguesa, nada tem de nacional, senão o nome de seus escritores, e o acaso de haverem no Brasil nascido. É fado que até este século que ora decorre, havendo o Brasil produzido tantos e tão grandes gênios, a todos ou a quase todos se possa imputar o defeito de imitares muito os escritores europeus, e de se não entregarem ao vôo livre de sua romanesca imaginação. ${ }^{47}$
\end{abstract}

Muito embora o foco da obra Parnaso Brasileiro, assim como a introdução que precede o livro, seja a situação da nossa literatura ontem e hoje não se encontra no respectivo livro uma definição, ainda que provisória, sobre a própria literatura. É necessário recuar um pouco no tempo para encontrá-la. Com isso, chega-se no ano de 1836. Essa data marca a publicação da segunda edição da Nitheroy, Revista Brasiliense de Ciências, Letras e Artes, revista fundada em Paris no mesmo ano, e do texto intitulado "Estudos sobre a Literatura", de Pereira da Silva, presente na segunda edição da Nitheroy. Não fugindo ao preceituário romântico, o autor vincula as palavras literatura e civilização, quando afirma que "A litteratura é sempre a expressão da civilisação; ambas caminham em paralelo [...] uma não se pode desenvolver sem a outra, ambas se erguem e caiem ao mesmo tempo". ${ }^{48}$ Conforme destaca Valdei Lopes de Araujo, "as 'letras' eram um marcador bastante objetivo do grau de civilização/perfeição alcançado por um povo". ${ }^{49}$ Em A experiência do tempo: conceitos e narrativas na formação nacional brasileira (1813-1845), o historiador tem como tarefa central refletir sobre as diferentes experiências do tempo, e a maneira de lidar com elas, produzidas por intelectuais do mundo luso-brasileiro nas primeiras décadas do século XIX. Com isso, argumenta-se que "se consolidou, ao longo da década de 30 , uma decisiva descontinuidade conceitual em resposta às novas formas de experimentar o tempo abertas com o processo de independência". ${ }^{50}$

No terceiro capítulo do livro, Araújo, a partir de texto de autores como Januário da Cunha Barbosa e Gonçalves de Magalhães, demonstra a maneira como se deu o surgimento de um novo conceito de literatura como expressão da nacionalidade. Esse aspecto é importante, pois o trabalho de Pereira da Silva insere-se dentro dessa discussão. Na verdade, segundo o

\footnotetext{
${ }^{46}$ Idem, pp. 170-171.

${ }^{47}$ Idem, p. 169. Grifo meu.

${ }^{48}$ SILVA, João Manuel Pereira da. "Estudos sobre a literatura". In: Nitheroy: revista brasiliense, sciencias, letras e artes, t. 1, n. 02,1836, p. 214.

49 ARAUJO, Valdei, Lopes de. A experiência do tempo: conceitos e narrativas na formação nacional brasileira (1813-1845). São Paulo: Aderaldo \& Rothschild, 2008, p. 108.

${ }^{50}$ Idem, p. 120.
} 
historiador “os 'Estudos sobre a Literatura' funcionam como uma espécie de explicação didática ao 'Ensaio' de Magalhães, esclarecendo aos nacionais que as idéias [...] estavam em sintonia com as novidades do Velho Mundo". 51

Pois bem, o autor de Plutarco Brasileiro tenta um esforço maior de reflexão, após uma definição que relacionava a literatura com a expressão da civilização. Já no parágrafo seguinte do "Estudos sobre a Literatura", ele busca explicar melhor e aprimorar a sua definição:

[...] a litteratura é hoje a reunião de tudo o que a imaginação exprime pela linguagem, abraçando todo o imperio em que exerce a intelligencia humana seu poderio; é o resumo dos habitos e grandeza dos povos, e a historia progressiva e circunstanciada do espírito humano com as suas superstiçoens, crenças, e carater proprio; é a apreciação da influência dos elementos uns sobre os outros no espírito das diferentes epochas, é a Philosophia, a Historia, a eloquência e a Poesia. ${ }^{52}$

O conceito é amplo o suficiente para abarcar a totalidade daquilo que é produzido pela inteligência humana. Por outro lado, essa concepção totalizante da literatura não possibilita diferenciar a própria literatura e os gêneros literários entre si. Já no que condiz à relação imaginação/linguagem, nota-se a inspiração buscada em Madame de Stäel, dentro do preceituário romântico. ${ }^{53}$

Após percorrer a marcha da literatura antiga e moderna e sempre objetivando vinculála com as formas de governo, a civilização e a religião, Pereira da Silva chega na última parte de seu texto e se concentra no que chama de o estado presente das letras. Dentre o amplo leque de domínios literários, a primazia é dada para a poesia. Para ele, a centralidade assumida pela poesia requeria do poeta ir além da sua função de compositor de versos e ser também “[...] historiador, plhilosopho, politico e artista, e que por tanto as dificuldades, que se lhe antolham, e que todas tem de vencer, para ganhar um nome, merecem todo o nosso respeito, e atenção". ${ }^{54}$ De todos os ramos abordados, poesia, eloquência, filosofia e história, Pereira da Silva procurava mostrar a contribuição brasileira, seja para criticar, seja para elogiar. A única exceção diz respeito à história. Quer fosse na sua forma particular, quer fosse na sua maneira universal, o Brasil não tinha ainda uma manifestação representativa desse gênero.

Em suma, a literatura passa a ser entendida como expressão da nacionalidade de uma sociedade e de um país. Ela, na expressão de Valdei Araujo, funcionará como uma cápsula do tempo, que se destinará à posteridade servindo de testemunho do grau de civilização de um

\footnotetext{
${ }^{51}$ Idem, p. 122.

${ }^{52}$ Idem, p 215. Grifo meu.

${ }^{53}$ Cf. ARAUJO, Valdei, Lopes de. A experiência do tempo... op. cit., p. 123. Cf. OLIVEIRA, Maria da Glória de. Escrever vidas, narrar a história... op. cit., p. 114.

${ }^{54}$ SILVA, João Manuel Pereira da. "Estudos sobre a literatura"... op. cit., p. 239.
} 
povo ou geração. A forma como o autor de "Estudos sobre a Literatura" organiza seu texto - a partir de uma única linha, elencando as diferentes modalidades literárias para chegar ao século XIX - deixa em segundo plano uma preocupação que poderia ser meramente descritiva e informativa sobre os escritores e suas obras. Não. Há na literatura uma tarefa mais pragmática e importante para a formação da nacionalidade de um país recém independente como o Brasil. ${ }^{55}$

\section{CONCLUSÃO}

Uma vida dividida entre o trabalho na advocacia, os debates parlamentares e a escrita histórica. Talvez sejam esses três aspectos que Pereira da Silva gostaria de ver ressaltados em sua biografia. Pode-se dizer que escrever sobre o outro implica, e muito, uma escrita sobre si mesmo, no sentido de que, por mais que estejamos concentrados em reproduzir o mais fidedignamente possível um retrato sobre um terceiro, há muito de nós mesmos naquilo que por ventura venhamos a relatar sobre alguém. Isso vale tanto para o passado quanto para o período contemporâneo com as profusões de biografias escritas recentemente. Com Plutarco Brasileiro, seu autor objetivava prestar um serviço ao país e fazer com que as gerações recentes tivessem modelos a se espalhar na constituição da nação.

Honrar a memória daqueles que já partiram, reforçar os laços de identidade e união naqueles que fazem parte de um império monárquico rodeado por repúblicas, a tarefa de escrever a história é nobre. Além de instruir e ser um guia para nossas ações, sejam elas pequenas ou grandiosas, a história também tem seu papel, não secundário, de inspirar o patriotismo. Dentro da escrita da história, o Brasil aparece ora como o continuador da tarefa civilizadora instaurada por Portugal, ora como um país que deveria construir seu próprio caminho de forma independente de sua antiga metrópole. Biografia, história e literatura, por conseguinte, mesclam-se na obra de Pereira da Silva tendo em vista um objetivo político e pragmático: reforçar o sentimento de pertencimento à incipiente nação.

\section{Recebido em: 08/04/2018 \\ Aceito em: 02/07/2018}

\footnotetext{
${ }^{55}$ Por isso a advertência do historiador: "O Brasil conta hoje bastantes litteratos profundos, porém elles tem-se tão somente contentado, (com algumas excepçoens) em estudar e saber, e não se têm querido dignar escrever, e d'est'arte esforçar-se em elevar á sua verdadeira essência esta sciencia, alias tão util e proveitosa á todas as classes da sociedade, e que de algum modo está desprezada na nossa Patria, não percebendo nossos compatriotas a influencia que ella tem sobre a política, sciencia do dia, á que hoje no Brasil todo o mundo se dá, sem se importar si o paiz por isso soffre". Idem, p. 217
} 


\section{REFERÊNCIAS BIBLIOGRÁFICAS}

BARBOSA, Januário da Cunha. "Discurso" Revista do Instituto Histórico e Geográfico Brasileiro, Rio de Janeiro, pp. 9-18.

CEZAR, Temístocles. "Livros de Plutarco: biografia e escrita da história no Brasil do século XIX”. Métis. História \& Cultura, v.2, n.3, jan./jun., 2003, pp. 73-94.

. "Lições sobre a escrita a história: as primeiras escolhas do IHGB. A historiografia brasileira entre os antigos e os modernos". In: Estudos de historiografia brasileira. Rio de Janeiro: FGV, 2011, pp. 93-124.

ENDERS, Armelle. "João Pereira da Silva, Francisco Adolfo Varnhagen et lês malheurs de

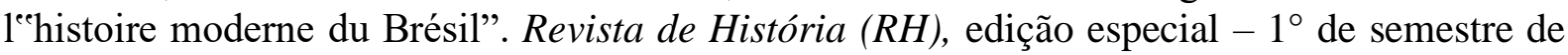
2010 - antigos, modernos e selvagens, pp. 115-129.

KOSELECK, Reinhart. "História magistra vitae. Sobre a dissolução do topos na história moderna em movimento. In: KOSELLECK, Reinhart. Futuro passado: contribuição à semântica dos tempos históricos. Rio de Janeiro: Contraponto, 2006, pp. 41-60.

LORIGA, Sabina. O pequeno x: da biografia à história. Belo Horizonte: Autêntica Editora, 2011.

“Des possibilités d'une histoire biographique". Comunicação apresentada na conferência proferida em 25 de setembro de 2006 no IFCH/UFRGS. Texto cedido pela autora. Agradeço ao professor Evandro dos Santos a disponibilidade do texto.

OLIVEIRA, Maria da Glória de. Escrever vidas, narrar a história: a biografia como problema historiográfico no Brasil oitocentista. RJ: Editora FGV, 2011.

"Biografia e historia magistra vitae: sobre a exemplaridade das vidas ilustres no Brasil oitocentista” Anos 90: Porto Alegre, v. 22, n. 42, p. 273-294, dez. 2015.

SILVA, João Manuel Pereira da. Plutarco Brasileiro. Rio de Janeiro: Em Casa dos Editores Eduardo e Henrique Laemmert, 1847. 2 Vol.

Os varões illustres do Brazil durante os tempos coloniáes. Pariz :

Livraria de A. Franck..., : Livraria de Guillaumin..., 1858. 2 v. 